\title{
Vanishing permanent glaciers: climate change is threatening a European Union habitat (Code 8340) and its poorly known biodiversity
}

\author{
M. Gobbi, R. Ambrosini, C. Casarotto, G. Diolaiuti, G. F. Ficetola, V. Lencioni, R. Seppi, C. Smiraglia, \\ D. Tampucci, B. Valle \& M. Caccianiga
}

Biodiversity and Conservation volume 30, pages 2267-2276 (2021)

Abstract

The cryosphere (i.e. glaciers and permafrost) and its related landforms offer a wide range of ecosystem services, thus they have strong relationships with human population. Even if these harsh environments have often been regarded as inhospitable, there is a growing amount of literature on glacial biodiversity, specifically concerning European mountains. Glaciers and permafrost-related landforms (e.g. rock glaciers) host a variety of cold-adapted taxa, from bacteria to vertebrates. They have been included in the Natura 2000 network, specifically in the habitat type: Permanent Glaciers (code 8340), but their biodiversity is still poorly known. Even if local extinctions and population reductions of cold-adapted species due to glacier and permafrost shrinking have been already documented, none of the species living in this habitat type are listed in the Habitat Directive Annexes. With this commentary, we call for urgent actions for an ecological characterization of this habitat type in order to plan monitoring and management of the biodiversity hosted by them. An increased knowledge of this no longer permanent habitat appears particularly urgent, because it is not replaceable and is likely to go extinct in the next decades.

International conventions are a cornerstone of biodiversity conservation, as they allow coordinated conservation and enforcement actions in several continents [e.g. CITES (1973); IUCN (2012); Council Directive 92/43/EEC (1992)]. The States belonging to the European Union have adopted the Habitat Directive [Council Directive 92/43/EEC (1992)] as one of the main tools to ensure the conservation of a wide range of rare, threatened and/or endemic plant and animal species and habitats. Over 1000 plant and animal species, as well as 233 habitat types listed in the directive's annexes are protected in various ways

(https://ec.europa.eu/environment/nature/legislation/habitatsdirective/index_en.htm). The Directive also led to the creation of a continental-scale network of protected areas-the Natura 2000 network - for the conservation of species and habitats listed in it. Urbanization, habitat alteration, resource consumption and environmental degradation are some of the major threats for biodiversity, specifically in mountain areas, which are also particularly vulnerable to ongoing climate change (Hock et al. 2019).

Changes of the physiognomy of high altitude landscapes and reduction of the mountain cryosphere (glaciers and permafrost) and its related landforms (Box 1 ) are among the most visible effects of climate change (Beniston et al. 2018; Adler et al. 2019; D'Agata et al. 2019). Glaciers are perhaps the 
most sensitive witnesses of climate change, given their fast area reduction (Diolaiuti et al. 2019). Glacier retreat leads to cascade effects on surrounding ecosystems, such as altered hydrological, thermal and bio-geochemical cycles and changes in the extent of glacier-fed streams and glacier forelands (Finn et al. 2010; Robinson et al. 2014; Hotaling et al. 2017; Brighenti et al., 2019). Permafrost is degrading under the effect of climate change as well, for instance through the thickening of the active layer and the reduction of its extent (see UNEP 2016; Biskaborn et al. 2019).

Glaciers and rock glaciers are climate-dependent landforms protected by the Habitat Directive by the habitat type "Permanent Glaciers-Code 8340" [Council Directive 92/43/EEC (1992)]. However, their management is particularly challenging because, as all high altitude habitats, they are changing at an unprecedented rate (Hock et al, 2019) and the ecological communities they host are suffering deep alterations due to species reduction, turnover and local (or global) extinction. In addition, despite this habitat has been included in the Habitat Directive, only a fraction of the surface actually covered by permanent glaciers is protected in the Natura 2000 network, leaving a significant fraction of the Habitat 8340 unprotected. Currently, the total number of sites, belonging to the European countries, linked to the habitat code 8340 is 123; specifically, half of them (61) in Italy, 25 in France, 12 in Spain, 11 in Austria, 10 in Sweden, two in Germany and two in Slovenia (https://natura2000.eea.europa.eu/\#).

On the base of the most widespread human perception, glaciers and related landforms are considered harsh environments not able to host living organisms. In contrast, a multitude of studies, many of them performed on the European Alps (see Brighenti et al. 2021), have demonstrated that they are ecosystems in their own right and are a permanent or temporary habitat for a large variety of cold-adapted organisms, from bacteria to vertebrates (Fig. 3). 


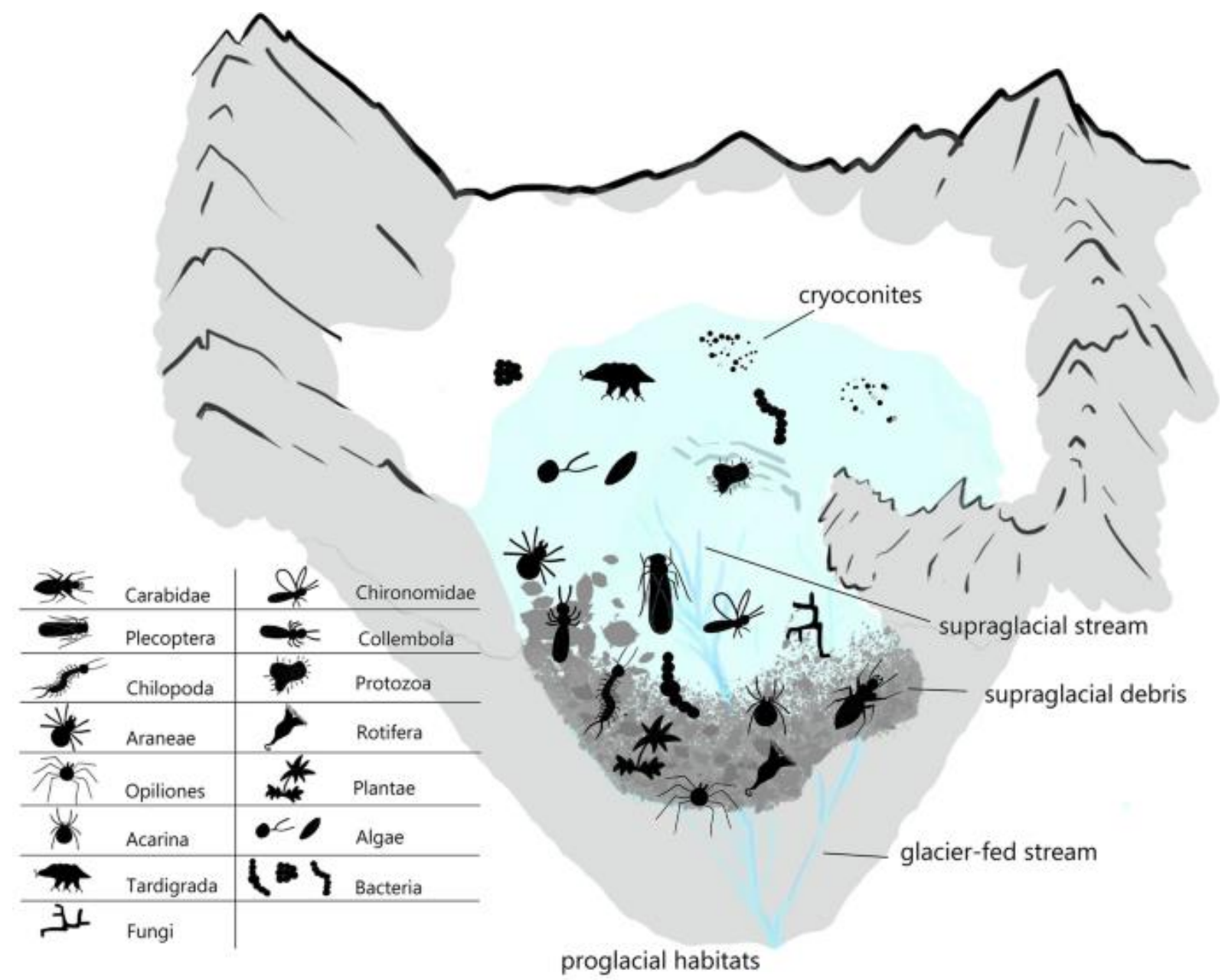

Fig. 3. Schematic representation of the organisms permanently living on a glacier (illustration by B. Valle)

The extreme specialisation of the organisms permanently living in these landforms makes them particularly threatened by the ongoing rapid climate warming (Cauvy-Fraunié and Dangles 2019; Anesio and Laybourn-Parry 2012; Rosvold 2016; Gobbi and Lencioni 2020; Stibal et al. 2020). Glaciers are a habitat much more complex and heterogeneous than commonly assumed. Life forms are found on their surface (supraglacial habitat), into the ice (englacial habitat), under the ice (subglacial habitat), close to them (proglacial habitat) and in glacier-fed streams and proglacial lakes and ponds.

The biodiversity hosted by glaciers, rock glaciers and recently deglaciated areas, as well as in glacierfed streams has been investigated generally by local-scale studies, which often focussed on some taxonomic groups like bacteria, yeasts, algae, plants, nematodes, rotifers, tardigrades, collembolans, insects and spiders (see. Gobbi et al. 2006; Caccianiga et al. 2011; Franzetti el al. 2013; Turchetti et al., 2013; Azzoni et al. 2015, Gobbi et al. 2017; Tampucci et al. 2017a; Lencioni 2018; Hågvar et al. 2020; Lencioni et al. 2021a; Tolotti et al. 2020; Zawierucha et al. 2019, 2021). However, our general knowledge of the biodiversity hosted by glacier environments is still incomplete from the taxonomical and biogeographical point of view. 
The occurrence of Habitat 8340 is largely determined by climatic factors and is at risk due to the rapid ongoing climate warming. Some model projections showed that some glaciers are going to be extinct in a few years or decades (Aili et al. 2019; Hock et al. 2019), and with them, probably, the associated local biodiversity. The monitoring and reporting performed under Article 17 of the Habitat Directive, described the status of the Habitat 8340 as unfavourable-bad (U2-the lowermost grade of the Habitat Directive ranking level) for 2013-2018 in all the European countries where it is present, and the same evaluation was given in the previous reporting period (2007-2012). The negative evaluation was reported for all the indicators of habitat status (range, surface, structure and function, future prospects) (https://bd.eionet.europa.eu/article17/reports2012/habitat/report).

From the conservation point of view, we must be aware that this habitat type is not replaceable. Although none of the species living on it are listed in the Natura 2000 Annexes, most of them deserve to be considered threatened by the Habitat 8340 areal reduction due to their (i) small population size, (ii) patchy or restricted distribution (i.e. steno-endemic species), (iii) low dispersal ability, and (iv) ability of surviving only under a narrow range of temperatures (Hotaling et al. 2017; Gobbi and Lencioni 2020). For instance, local extinction of cold adapted aquatic (e.g. the Chironomid Diamesa steinboecki) and terrestrial (e.g. the Carabid Nebria germari) insect species typical of glacial habitats have been already observed in different areas of the Italian Alps (Lencioni et al. 2021a; Gobbi 2020; Valle et al. 2020). Furthermore, several taxa are likely still unknown, particularly in the least accessible high-alpine areas or mountain groups. In fact, many species living in this habitat probably have a much smaller distribution range than generally assumed, due to the presence of cryptic species (e.g. Bálint et al. 2011), and some endemic taxa are likely still not described and at the risk of extinction even before being described and having DNA sequences deposited (Lencioni et al., 2021b).

An ecological characterisation of Habitat 8340 is mandatory before glaciers and permafrost-related landforms become extinct or heavily reduced in Europe, and with them most of the associated biodiversity, which belongs to the naturalistic and cultural heritage at continental scale. Such characterisation should take into account the different landforms included within the Habitat Directive, such as debris-free and debris-covered glaciers, rock glaciers, proglacial environment, glacier-fed water bodies. Presently, following the interpretation manual of European Union Habitats (https://ec.europa.eu/environment/nature/legislation/habitatsdirective/docs/Int_Manual_EU28.pdf) , Habitat 8340 includes "rock and true glaciers". National monitoring guidelines (e.g. Angelini et al. 2016) provide a more detailed description of the habitat type, which includes glaciers, debriscovered glaciers and rock glaciers, but countries give different interpretations to Habitat 8340 . This is evident from the heterogeneous lists of "typical species" provided by member states to assess the parameter of habitat's "structure and function". Some countries (e.g. Austria, Italy) only list strictly supraglacial organisms (mainly algae), suggesting a narrow correspondence of the Habitat with debris-free glaciers, while other countries (Germany, Spain) also include plant species linked to a much wider range of environmental condition, even subalpine shrubs like Rhododendron ferrugineum (http://cdr.eionet.europa.eu/help/habitats_art17). This highlights the need for a uniform, comprehensive and updated definition of the Habitat and of the species living in it. 
We would like to draw the attention on glaciers, particularly debris-covered glaciers, and on rock glaciers. Debris-free glaciers are mainly colonised by bacteria, algae, arthropods (e.g. Coleoptera Carabidae, Diptera Chironomidae, Plecoptera, Araneae, Acarinae, Collembola), and are periodically or seasonally frequented by birds and mammals (Rosvold 2016, Gobbi and Lencioni 2020). In addition, whenever present, cryoconite holes (water-filled holes on glacial ice surface, in which darkcoloured aggregate of mineral particles and organic matter is deposited), are biodiversity hotspots where bacteria, algae, and several invertebrate taxa (e.g. Tardigrada, Annelida, Copepoda, Rotifera and Collembola) live (Zawierucha et al. 2021). Debris-covered glaciers host an even higher biodiversity also because their tongue, protected from intense ablation by the debris cover, can reach lower altitudes than that of clean-ice glaciers, even below the treeline. Indeed, besides the above-listed taxa, a diversified moss, vascular plant and invertebrate community is able to live on supraglacial debris (Caccianiga et al. 2011; Fickert et al. 2007; Pelfini et al. 2007; Gobbi and Lencioni 2020).

Rock glaciers are deeply different from glaciers as they are characterized by peculiar processes at their surface and inside them (Haeberli 1985) and by different biocoenoses on their surface (Cannone and Gerdol 2003; Burga et al. 2004; Gobbi et al. 2014; Tampucci et al. 2017b). Furthermore, there is an increasing agreement about the role of debris-covered glaciers and rock glaciers as potential refuge areas, in the present warming period, for some cold-adapted species threatened by summit traps in mountain areas (Fickert et al. 2007; Gentili et al. 2015a, 2015b; Tampucci et al. 2017a; Gobbi and Lencioni 2020).

Habitat 8340 is important also for humans, particularly for provisioning (e.g. tourism, industrial activities and "water tower" sensu Immerzeel et al. (2020)) and cultural (including recreational, e.g. mountain sport, and theatres of World War I) ecosystem services (Stewart et al. 2016; Milner et al. 2017; Palomo 2017). Being mainly a phenomenon due to global drivers, it is inconceivable to stop glacial retreat or permafrost thaw through local management strategies. To our knowledge, no action has been developed to mitigate the effect of climate change on this habitat type since the mechanisms driving its dynamics and ecology are still poorly known. Anyway, we cannot continue to ignore the crisis of this habitat type and its associated biodiversity, specifically when actions of habitat monitoring-in natural reserves-are in the planning phase. The poor knowledge we have of this no longer permanent habitat urges to increase the number of studies assessing the status and trends of this Natura 2000 habitat type and its connected biodiversity, in order to develop a European Glacial Biodiversity Monitoring Programme similar to the ongoing Circumpolar Biodiversity Monitoring Programme (see Christensen et al. 2020). Indeed, the spatial and temporal dynamics of the species assemblages linked to the Habitat 8340 is revealing a rapid turnover of species with the substitution of cold-adapted species with more eurythermal species (Lencioni 2018; Hagvar et al. 2020). This pattern deserves to be monitored for better planning conservation of this habitat type. 